\title{
Dynamic Analysis of Coupling Vehicle-Bridge System Using Finite Prism Method
}

\author{
A. T. Saeed and Zhongfu Xiang
}

\begin{abstract}
To investigate the transient responses of bridges under moving vehicles, Finite Prism method was employed. In this method a combination of the finite element method representing the cross-section of the prism and Fourier series suitably chosen to represent the behavior of prism in the longitudinal direction (which satisfies the simply supported boundary conditions at the ends), is used. Explicit time integration scheme was used for solving the equation of motion for both the bridge and the vehicle. The damping was neglected in the formulation of the equation of motion of the bridge. This render was used to avoid the solution of global system of equations, because each equation becomes uncoupled with other equations. One of the main aspects in the present work is the coupling of the explicit solution technique of the equation of motion with the harmonic solution, using finite prism method for the problem of moving vehicles, taking into consideration the dynamic coupling between the vehicle and the bridge.
\end{abstract}

Index Terms-Finite prism, moving vehicles, moving forces, vehicle-bridge coupling, explicit time integration scheme.

\section{INTRODUCTION}

The purpose of this work is to develop a procedure for obtaining the dynamic response of bridges subjected to moving vehicles. Naturally, the bridges are three dimensional structures. The finite prism method was first developed by Zienkiewics and Too [1] for the static analysis of bridges and also developed for the free vibration analysis of straight and curved deck and box girder bridges by AL-Darzi [2]. The same method is developed and used in the present work, for the first time, for the dynamic analysis of bridges due to moving vehicles. In this method, a combination of the finite element method representing the cross section of the prism and Fourier series suitably chosen to represent the behavior of the prism in the longitudinal direction, (which satisfies the simply supported boundary conditions at the ends), is used. Moreover, the three dimensional problem is reduced to a series of two dimensional problems, which are decoupled for each harmonic number.

The explicit time integration scheme is used for solving the equation of motion for each of the bridge and the vehicle. These afford avoiding the solution of global system of equations, because each equation becomes uncoupled with other equations.

One of the main aspects of the present work is the coupling

Manuscript received September 29, 2016; revised November 23, 2016 This work was supported in part by Chongqing Jiaotong University and the Postdoctoral Research Foundation of China under Grant RC201558. We acknowledge their beneficial supports.

The authors are with the Civil Engineering and Architecture School, Chongqing Jiaotong University, Chongqing, 400074, China (e-mail: atsaeed75@yahoo.com, xzf6058@126.com). of the explicit solution technique of the equation of motion with harmonic solution using the finite prism method for the problem of moving vehicle, taking into consideration the dynamic interaction between the vehicle and the bridge. Two models of vehicle have been used: In the first model, called the moving force model, the inertia force of the vehicle and the dynamic interaction between the vehicle and the bridge has been neglected. In the second model, called the moving vehicle model, the vehicle is represented by a spring mass system in which the inertia force of the vehicle and the dynamic interaction between the spring mass system and the vibration of the bridge is taking into consideration.

The validity of the developed numerical model has been studied by analyzing structures such as simply supported plates and beams subjected to moving vehicles with different speeds, for the two models of vehicles. Comparison with the available reported results has shown a significant matching.

\section{FINITE PRISM FORMULATION}

The three dimensional displacement components can be written as:

$$
\{q\}=\left\{\begin{array}{l}
u \\
v \\
w
\end{array}\right\}
$$

where $u, v$ and $w$ are the displacements along the three dimensional Cartesian axes $\mathrm{X}, \mathrm{Y}$ and $\mathrm{Z}$, respectively as shown in Fig. 1:

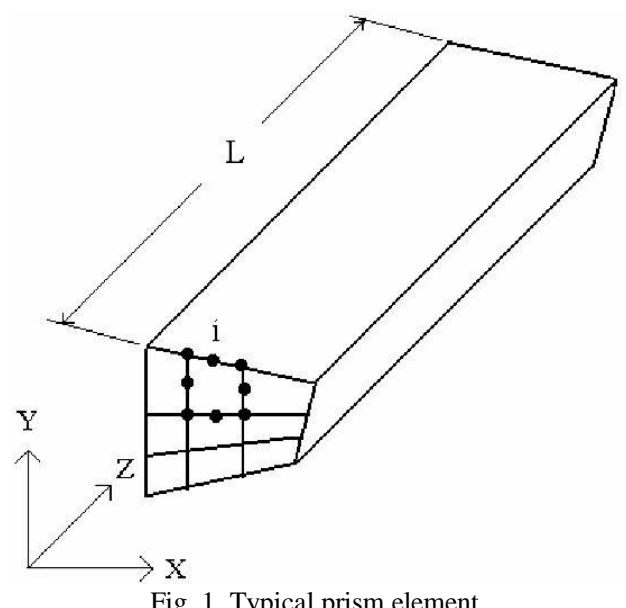

The displacement at any point in the eight-node prism element can be interpolated as follows [1], [2]:

$$
u(r, s, z)=\sum_{l=1}^{\infty} \sum_{i=1}^{n e} N_{i}(r, s) u_{i}^{l} \sin \frac{l \pi z}{L}
$$




$$
\begin{aligned}
& v(r, s, z)=\sum_{l=1}^{\infty} \sum_{i=1}^{n e} N_{i}(r, s) v_{i}^{l} \sin \frac{l \pi z}{L} \\
& w(r, s, z)=\sum_{l=1}^{\infty} \sum_{i=1}^{n e} N_{i}(r, s) w_{i}^{l} \sin \frac{l \pi z}{L}
\end{aligned}
$$

where $u_{i}^{l}, v_{i}^{l}$ and $w_{i}^{l}$ are the nodal line displacements amplitudes for harmonic number $l$ at node $i$ for prism $e$, ne is the total number of nodal lines for the prism which is equal to eight, $N_{i}$ is the interpolation (shape) function in terms of the local coordinates $r, s$ which vary from -1 to +1 within the cross section of the prism.

The discretized expression for strains and stresses within an element can be expressed as [3]:

$$
\begin{gathered}
\{\varepsilon\}=\sum_{l=1}^{\infty} \sum_{i=1}^{n e}\left[B_{i}^{l}\right]\left\{d_{i}^{l}\right\} \\
\{\sigma\}=[D] \sum_{l=1}^{\infty} \sum_{i=1}^{n e}\left[B_{i}^{l}\right]\left\{d_{i}^{l}\right\}
\end{gathered}
$$

where $[D]$ is the elasticity matrix [4] and the strain-displacement matrix $\left[B_{i}^{l}\right]$ associated with nodal line $i$ for the harmonic $l$ can be expressed as [2]:

$$
\begin{aligned}
& {\left[B_{i}^{l}\right]=\left[\begin{array}{ccc}
\frac{\partial N_{i}}{\partial x} S l & 0 & 0 \\
0 & \frac{\partial N_{i}}{\partial y} S l & 0 \\
0 & 0 & -\frac{l \pi}{L} N_{i} S l \\
\frac{\partial N_{i}}{\partial y} S l & \frac{\partial N_{i}}{\partial x} S l & 0 \\
\frac{l \pi}{L} N_{i} C l & 0 & \frac{\partial N_{i}}{\partial x} C l \\
0 & \frac{l \pi}{L} N_{i} C l & \frac{\partial N_{i}}{\partial y} C l
\end{array}\right]} \\
& \left\{d_{i}^{l}\right\}=\left[u_{i}^{l}, v_{i}^{l}, w_{i}^{l}\right]^{T}
\end{aligned}
$$

The strain and stress components in vector form can be written as:

$$
\begin{gathered}
\{\varepsilon\}=\left\{\varepsilon_{x}, \varepsilon_{y}, \varepsilon_{z}, \gamma_{x y}, \gamma_{x z}, \gamma_{y z}\right\}^{T} \\
\{\sigma\}=\left\{\sigma_{x}, \sigma_{y}, \sigma_{z}, \tau_{x y}, \tau_{x z}, \tau_{y z}\right\}^{T}
\end{gathered}
$$

\section{DYNAMIC EQUATIONS}

The dynamic equation of motion of bridge can be expressed as:

$$
[M]\{\ddot{d}\}+[C]\{\dot{d}\}+[K]\{d\}=\left\{F_{t}\right\}
$$

where $[M],[C]$ and $[K]$ are the global mass, damping and stiffness matrices, respectively; and $\{\ddot{d}\},\{\dot{d}\}$ and $\{d\}$ are the acceleration, velocity and displacement vectors, respectively.
$\left\{F_{t}\right\}$ is the external applied load, which is function of time $t$. The damping matrix can be written as $[5,6]$ :

$$
[C]=\int_{v}[N]^{T} C[N]
$$

Due to the orthogonality properties [2] i.e.;

$$
\left.\begin{array}{l}
\int_{o}^{L} \sin \frac{l \pi z}{L} \cdot \sin \frac{m \pi z}{L} d z \\
\int_{o}^{L} \cos \frac{l \pi z}{L} \cdot \cos \frac{m \pi z}{L} d z
\end{array}\right\}=0 \text { when } l \neq m
$$

The stiffness and mass matrices for harmonic $l$ can be written as:

$$
\begin{gathered}
\{\varepsilon\}=\sum_{l=1}^{\infty} \sum_{i=1}^{n e}\left[B_{i}^{l}\right]\left\{d_{i}^{l}\right\} \\
{\left[M_{i j}^{l l}\right]=\frac{L}{2} \iint_{A}\left[N_{i}^{l}\right]^{T} \rho\left[N_{j}^{l}\right] d x \cdot d y}
\end{gathered}
$$

The equivalent nodal force vector can be expressed as:

$$
\left\{F_{t}\right\}=\sum_{l=1}^{\infty} \sum_{i=1}^{n e}\left[\begin{array}{ccc}
N_{i} . S l & 0 & 0 \\
0 & N_{i} . S l & 0 \\
0 & 0 & N_{i} . C l
\end{array}\right]\left\{f_{p}\right\}
$$

The integration of stiffness and mass matrices are carried out numerically using Gauss quadrature method.

\section{VEHICLE-BRIDGE COUPLING SYSTEM}

\section{A. Vehicle Models}

The two vehicle models moving over the bridge are shown in Fig 2. In the first model the vehicle is represented as a moving force in which the dynamic interaction between the vehicle and the bridge is neglected. In the second model, called the moving vehicle model, the vehicle is represented by a single degree of freedom system comprising sprung mass $\left(m_{v}\right)$ and unsprung mass $\left(m_{t}\right)$ with viscous damping $\left(c_{v}\right)$ included in the suspension, $\left(k_{v}\right)$ is the stiffness of the vehicles. It is assumed that the vehicle travels at constant velocity and that the unsprung wheel is always in contact with the road surface which is assumed to be smooth.

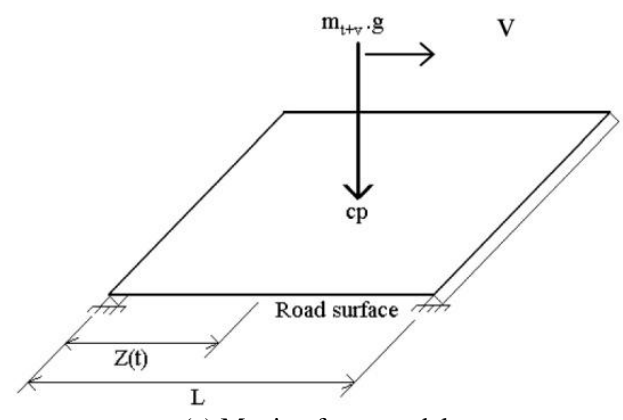

(a) Moving force model 


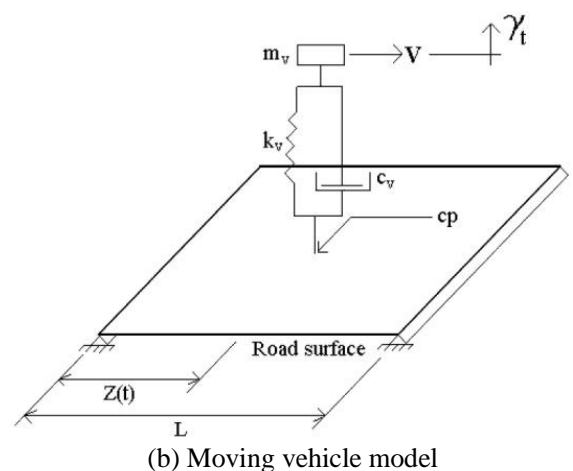

(b) Moving vehicle model

Fig. 2. Vehicle models

\section{B. Solution of the Equation of Motion}

The integration of the equation of motion (9) is carried out using the explicit central difference scheme [7], [8]. This is only applicable when the mass matrix is lumped mass matrix. This requires the transformation of constant mass matrix in (13) into a lumped mass matrix as in the following.

\section{Mass Lumping}

The most simple method of lumping the prism mass matrix is by adding all terms of each line of the consistent mass matrix and placing the result on the diagonal, such a process gives the nodal masses in the following form [9], [10]:

$$
\bar{M}_{i i}^{e}=\sum M_{i j}^{e}
$$

This method fails when applied to eight-node isoparametric element. The reason is that negative nodal masses are obtained in corner nodes. To overcome this, several alternative schemes have been investigated in the literature [10]. In the present work a new approach was developed in which the total mass of the element is divided equally between mid- side and corner nodes as follows:

$$
\bar{M}_{i i}^{e}=\frac{1}{8} M^{e}
$$

In another approach suggested by Owen and Hinton and by others $[8,10,11,12]$, the mass is lumped to the diagonal terms of the consistent mass matrix, as follows:

$$
\begin{aligned}
& \bar{M}_{i i}^{e}=M_{i i}^{e}\left(\frac{M^{e}}{\sum M_{i i}^{e}}\right) \\
& M_{i i}^{e}=\int_{v} N_{i}^{2} \rho d v
\end{aligned}
$$

where $M^{e}$ is the total mass of the element. This procedure is also used in the present work and both approaches gave almost same results.

\section{EXPLICIT TIME INTEGRATION SCHEME}

The dynamic equation of motion for harmonic $l$ can be written at time $t$ as:

$$
[M]\left\{\ddot{d}_{t}\right\}^{l}+[C]\left\{\dot{d}_{t}\right\}^{l}+\left\{P_{t}\right\}^{l}=\left\{F_{t}\right\}^{l}
$$

where $\left\{P_{t}\right\}^{l}$ is the global vector of internal resisting nodal forces and $\left\{F_{t}\right\}^{l}$ is the vector of equivalent nodal forces resulting from the dynamic interaction force between the vehicle and bridge $f^{c p}$ at the contact point $c p$.

The dynamic interaction force $f^{c p}$ is a function of the displacement, velocity and acceleration at contact point $d_{t}^{c p}$, $\dot{d}_{t}^{c p}$ and $\ddot{d}_{t}^{c p}$.

In the central difference approximation, the acceleration can be written as follows:

$$
\left\{\ddot{d}_{t}\right\}^{l}=\frac{1}{(\Delta t)^{2}}\left[\left\{d_{t+\Delta t}\right\}^{l}-2\left\{d_{t}\right\}^{l}+\left\{d_{t-\Delta t}\right\}^{l}\right]
$$

and the velocity may also be expressed as follows:

$$
\left\{\dot{d}_{t}\right\}^{l}=\frac{1}{2(\Delta t)}\left[\left\{d_{t+\Delta t}\right\}^{l}-\left\{d_{t-\Delta t}\right\}^{l}\right]
$$

Substituting (19) and (20) in (18) and solving for $\left\{d_{t+\Delta t}\right\}^{l}$ yields:

$$
\begin{aligned}
& \left\{d_{t+\Delta t}\right\}^{l}=\left([M]+\frac{\Delta t}{2}[C]\right)^{-1} \\
& {\left[(\Delta t)^{2}\left\{R_{t}\right\}^{l} 2[M]\left\{d_{t}\right\}^{l}\left([M]-\frac{\Delta t}{2}[C]\right)\left\{d_{t-\Delta t}\right\}^{l}\right]}
\end{aligned}
$$

where $\left\{R_{t}\right\}^{l}$ is the residual force vector at time $t$, which is equal to:

$$
\left\{R_{t}\right\}^{l}=\left\{F_{t}\right\}^{l}-\left\{P_{t}\right\}^{l}
$$

If the matrices $[M]$ and $[C]$ are both diagonal matrices then the solution of (21) for degree of freedom $i$ can be easily written as follows:

$$
\begin{aligned}
& \left(d_{i}\right)_{t+\Delta t}^{l}=\left(m_{i i}+\frac{\Delta t}{2} c_{i i}\right)^{-1} \\
& {\left[(\Delta t)^{2}\left(r f_{i}\right)_{t}+2 m_{i i}\left(d_{i}\right)_{t}^{l}-\left(m_{i i}-\frac{\Delta t}{2} c_{i i}\right)\left(d_{i}\right)_{t-\Delta t}^{l}\right]}
\end{aligned}
$$

where $\left(d_{i}\right)_{t+\Delta t}^{l}$ is the displacement in the $i^{\text {th }}$ degree of freedom for harmonic number $l ; m_{i i}$ and $c_{i i}$ are the corresponding diagonal terms of the mass and damping matrices, and $r f_{i}$ is the corresponding component of residual force vector.

\section{Starting AlgORITHM}

Since the governing equilibrium equation (23) or (21) involves information at the previous time steps $t$ and $t-\Delta t$, a starting algorithm is therefore required. Based on the initial conditions, the value at $0-\Delta t$ may be obtained from (20).

$$
\left(\dot{d}_{l}\right)_{0}^{l}=\frac{1}{2(\Delta t)}\left[\left(d_{i}\right)_{0+\Delta t}^{l}-\left(d_{i}\right)_{0-\Delta t}^{l}\right]
$$

from which, we get:

$$
\left(d_{i}\right)_{0-\Delta t}^{l}=-2 \Delta t\left(\dot{d_{l}}\right)_{0}^{l}+\left(\dot{d_{l}}\right)_{0+\Delta t}^{l}
$$


Substituting (25) in (23), the displacements of the $i^{\text {th }}$ degree of freedom at the first time step $\Delta t$ for harmonic $l$ can be evaluated as follows:

$$
\begin{aligned}
\left(d_{i}\right)_{\Delta t}^{l}= & \frac{(\Delta t)^{2}}{2 m_{i i}}\left(r f_{i}\right)_{0}^{l}+\left(d_{i}\right)_{0}^{l} \\
& +\Delta t\left[1-\frac{c_{i i} \Delta t}{2 m_{i i}}\right]\left(\dot{d}_{l}\right)_{0}^{l}
\end{aligned}
$$

It is reported in the literatures [13], [14], [15], [16], that the damping effect of the bridge is small and can be neglected in the analysis. The explicit algorithm is conditionally stable and it requires small time steps for accurate and stable solution. In the present work the estimation of critical time step given by Tsui and tony [17] was adopted.

\section{DyNAMIC CONDITION AT CONTACT PoINT}

The vertical displacement at the vehicle contact point $d_{t+\Delta t}^{c p}$ can be interpolated from the nodal displacement amplitudes at time step $t+\Delta t$, i.e. $\left\{d_{t+\Delta t}\right\}^{l}$ by using (2). Also, the velocity at the contact point at time step $t+\Delta t$ can be determined by backward finite difference scheme using the contact point displacement at time steps $t$ and $t+\Delta t$ as [3]:

$$
\dot{d}_{t+\Delta t}^{c p}=\frac{1}{\Delta t}\left[d_{t+\Delta t}^{c p}-d_{t}^{c p}\right]
$$

\section{MOVING VeHICLE RESPONSE}

The nodal force vector due to moving vehicle at time step $t+\Delta t$ for each harmonic term $\left\{F_{t+\Delta t}\right\}^{l}$ consists of several terms. The nodal force due to the contact force between the vehicle and the bridge $f_{t+\Delta t}^{c p}$ can be determined for the two vehicle models as follows:

\section{A. Moving Force Model}

For the moving force model in Fig. 2-a, the applied force on the bridge is due to the vehicle weight, which moves at constant speed, and its position is a function of time only. The force at the vehicle contact point can be calculated as follows :

$$
f_{t+\Delta t}^{c p}=-m_{t+v} \cdot g
$$

Then the nodal force vector for all harmonic numbers at time step $t+\Delta t$ can be calculated using (14) and the amplitude displacement for each harmonic at time step $t+\Delta t$ can be determined by (23).

\section{B. Moving Vehicle Model}

For the moving vehicle model shown in Fig. 2-b, the applied force on the bridge is due to the dynamic interaction between the vehicle and the bridge. The equation of motion for the moving vehicle model can be written as follows [3]:

$$
\begin{gathered}
m_{t} \ddot{d}_{t+\Delta t}^{c p}+c_{v}\left(\dot{d}_{t+\Delta t}^{c p}-\dot{\gamma}_{t+\Delta t}\right)+k_{v}\left(d_{t+\Delta t}^{c p}-\gamma_{t+\Delta t}\right) \\
=-m_{t} . g
\end{gathered}
$$

$$
\begin{gathered}
m_{v} \ddot{\gamma}_{t+\Delta t}+c_{v}\left(\dot{\gamma}_{t+\Delta t}-\dot{d}_{t+\Delta t}^{c p}\right)+k_{v}\left(\gamma_{t+\Delta t}-d_{t+\Delta t}^{c p}\right) \\
=-m_{v} \cdot g
\end{gathered}
$$

The displacement and velocity of the sprung mass at time step $t+\Delta t$ i.e. $\gamma_{t+\Delta t}$ and $\dot{\gamma}_{t+\Delta t}$, respectively, can be determined depending on the known values of $d_{t+\Delta t}$ and $\dot{d}_{t+\Delta t}$ by solving the equation of motion of the vehicle (29) using explicit time integration scheme. After a mathematical manipulation and simplification, the solution of $\gamma_{t+\Delta t}$ can be written as :

follows

$$
\begin{aligned}
\gamma_{t+\Delta t}= & \frac{1}{\left(m_{v}+\frac{\Delta t}{c} c_{v}\right)}\left[(\Delta t)^{2}\left(R_{t}-k_{v} \gamma_{t}\right)\right. \\
& \left.+2 m_{v} \gamma_{t}\left(m_{v}-\frac{\Delta t}{2} c_{v}\right) \gamma_{t+\Delta t}\right]
\end{aligned}
$$

where

$$
R_{t}=-m_{v} \cdot g+c_{v} \dot{d}_{t+\Delta t}^{c p}+k_{v} d_{t+\Delta t}^{c p}
$$

To calculate $\gamma_{\Delta t}$ at timet $=\Delta t$, the term $\gamma_{0-\Delta t}$ has to be known beforehand. So a starting algorithm is necessary and $\gamma_{\Delta t}$ can be determined as follows:

$$
\begin{gathered}
\gamma_{\Delta t}=\frac{(\Delta t)^{2}}{2 m_{v}}\left(R_{0}-k_{v} \gamma_{0}\right)+\gamma_{0} \\
+\Delta t\left[1-\frac{c_{v} \Delta t}{2 m_{v}}\right] \dot{\gamma}_{0}
\end{gathered}
$$

The initial condition of the vehicle and the bridge at the contact point can be written as:

$$
d_{0}^{c p}=0, \dot{d}_{0}^{c p}=0, \ddot{d}_{0}^{c p}=0, \dot{\gamma}_{0}=0 \text { and } \ddot{\gamma}_{0}
$$

By substituting these conditions in the previous equations, the initial value of $\gamma$ can be determined as:

$$
\gamma_{0}=\frac{-m_{v} \cdot g}{k_{v}}
$$

Then the interaction force at contact point at time step $t+\Delta t$ i.e. $f_{t+\Delta t}^{c p}$ can be determined as follows:

$$
f_{t+\Delta t}^{c p}=-\left(m_{t}+m_{v}\right) \cdot g-m_{v} \ddot{\gamma}_{t+\Delta t}-m_{t} \ddot{d}_{t+\Delta t}^{c p}
$$

Substituting (35) in (29-b) yield:

$$
\begin{aligned}
f_{t+\Delta t}^{c p}=-m_{t} \ddot{d}_{t+\Delta t}^{c p}+c_{v}\left(\dot{\gamma}_{t+\Delta t}-\dot{d}_{t+\Delta t}^{c p}\right) \\
+k_{v}\left(\gamma_{t+\Delta t}-d_{t+\Delta t}^{c p}\right)-m_{t} \cdot g
\end{aligned}
$$

In view of the fact that the wheel mass $m_{t}$ is very small in comparison with the vehicle mass $m_{v}$, it can be neglected in (36), and accordingly this equation can be rewritten as follows:

$$
c_{v}\left(\dot{\gamma}_{t+\Delta t}-\dot{d}_{t+\Delta t}^{c p}\right)+k_{v}\left(\gamma_{t+\Delta t}-d_{t+\Delta t}^{c p}\right)
$$

The velocity of the sprung mass $\dot{\gamma}_{t+\Delta t}$ can be calculated by using backward finite difference as follows:

$$
\dot{\gamma}_{t+\Delta t}=\frac{1}{\Delta t}\left[\gamma_{t+\Delta t}-\gamma_{t}\right]
$$




\section{VALIDATION OF THE METHOD}

\section{A. Moving Force Model}

In order to confirm the accuracy of the developed numerical model, a simply supported plate at two opposite edges and subjected to a moving force, as shown in Fig. 3, was first considered, then the plate cross section is divided into five prism elements. The information in Table I gives details of the material properties and the moving force:

TABLE I: PROPERTIES OF Plate MATERIAL AND MOVING ForCE

\begin{tabular}{ll}
\hline \hline Item & Value \\
\hline Moving force & $4.4482 \mathrm{~N}$ \\
Force speed & $96.56 \mathrm{~km} / \mathrm{h}$ \\
Modulus of elasticity (E) & $20684.4 \mathrm{MPa}$ (concrete) \\
Mass density & $2400 \mathrm{~kg} / \mathrm{m}^{3}$ \\
Poisson's ratio & 0.15 \\
Plate thickness & $0.4572 \mathrm{~m}$ \\
\hline \hline
\end{tabular}

The dynamic response of this plate under a moving force is presented in terms of the normalized centre displacements, as shown in Fig. 4. The normalized centre displacement is defined as (the ratio of the dynamic centre displacement to the maximum static centre displacement when the load is at any point along the span). The present results are compared with those of Srinivasan and Munaswamy [18] using the finite strip method. Fig. 4 shows the relation of the normalized displacement at the centre of the plate with the normalized position of the vehicle along the span of the plate. It can be noticed from this figure that when the vehicle leaves the plate, the normalized displacement at the centre of the plate is of the order 0.16 which is due to the inertia force of the plate.

\section{B. Moving Vehicle Model}

A simply supported beam with the geometry shown in Fig. 5, was subjected to a moving vehicle model and has been analyzed. The beam cross section is divided into four prism elements. The details of the material properties and moving vehicle model are given in Table II:

TABLE II: PROPERTIES OF BEAM MATERIAL AND MOVING VEHICLE

\begin{tabular}{ll}
\hline \hline Item & Value \\
\hline Sprung vehicle mass $\left(m_{v}\right)$ & $1000 \mathrm{~kg}$ \\
Vehicle viscous damping $\left(c_{v}\right)$ & $8.54 \mathrm{~N} . \mathrm{s} / \mathrm{mm}$ \\
Vehicle stiffness $\left(k_{v}\right)$ & $292 \mathrm{~N} / \mathrm{mm}$ \\
Modulus of elasticity $(\mathrm{E})$ & $22000 \mathrm{MPa}$ (concrete) \\
Mass density & $2400 \mathrm{~kg} / \mathrm{m}^{3}$ \\
Poisson's ratio & 0.15 \\
Span length & $5 \mathrm{~m}$ \\
\hline \hline
\end{tabular}

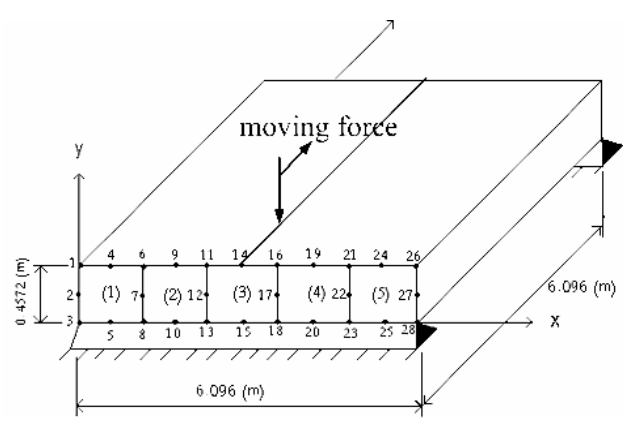

Fig. 3. Geometry and finite prism idealization of two opposite edges simply supported plate.

The analysis is carried out using five harmonic terms only. The predicted dynamic response is compared with that of Cai et al. [19] as shown in Fig. 6 and Fig. 7. It can be noticed that by increasing the speed of the vehicle up to $590.4 \mathrm{~km} / \mathrm{h}$; the maximum normalized displacement takes place when the vehicle is at about 0.7 of the span length, while when the vehicle moves at speed of $295.2 \mathrm{~km} / \mathrm{h}$ the maximum normalized displacement takes place when the vehicle is at about 0.4 of the span.

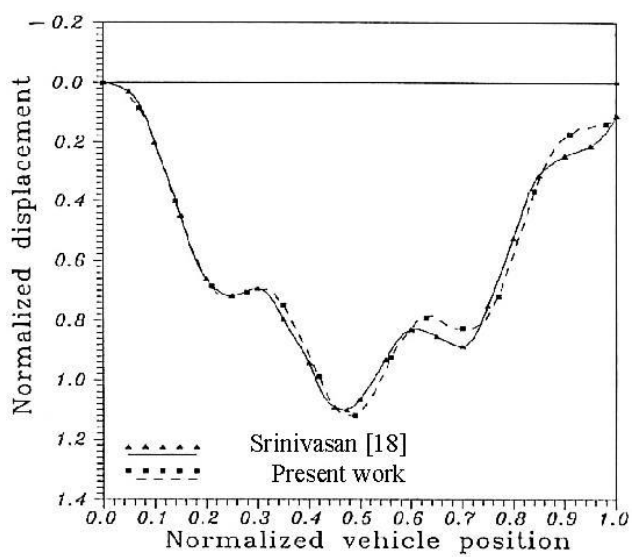

Fig. 4. Normalized centre displacement of simply supported plate.

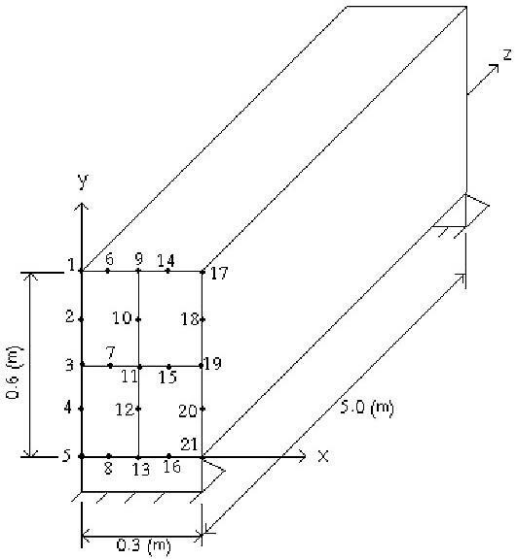

Fig. 5. Geometry and finite prism idealization of simply supported beam.

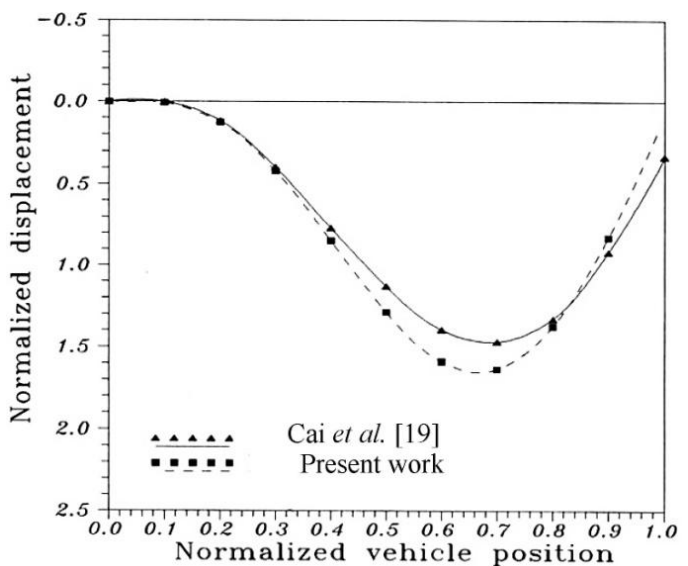

Fig. 6. Normalized centre displacement of simply supported beam due to vehicle speed $590.4 \mathrm{~km} / \mathrm{h}$

\section{DyNAMIC ANALYSIS OF DECK GIRDER BRIDGE}

A simply supported deck girder bridge, with the geometry shown in Fig. 8, was subjected to vehicle model moving over the central girder. The bridge cross-section is divided into 25 prism elements as shown in Fig. 9. The details of the material properties and moving vehicle model is given in Table III: 


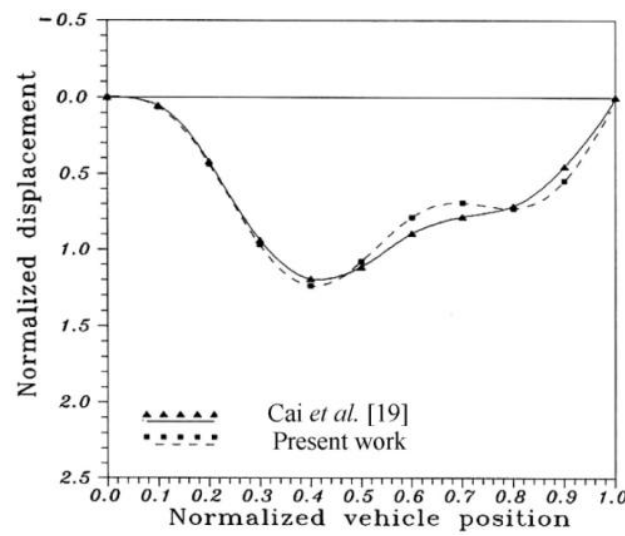

Fig. 7. Normalized centre displacement of simply supported beam due to vehicle speed $295.2 \mathrm{~km} / \mathrm{h}$.

TABLE III: PROPERTIES OF BRIDGE MATERIAL AND MOVING VEHICLE

\begin{tabular}{ll}
\hline \hline Item & Value \\
\hline Vehicle Speeds & Vary from $40 \mathrm{~km} / \mathrm{h}$ to $100 \mathrm{~km} / \mathrm{h}$ \\
Sprung vehicle mass $\left(m_{v}\right)$ & $20394 \mathrm{~kg}$ \\
Vehicle viscous damping $\left(c_{v}\right)$ & $69.12 \mathrm{~N} . \mathrm{s} / \mathrm{mm}$ \\
Vehicle stiffness $\left(k_{v}\right)$ & $5971.97 \mathrm{~N} / \mathrm{mm}$ \\
Modulus of elasticity $(\mathrm{E})$ & $20000 \mathrm{MPa}$ (concrete) \\
Mass density & $2400 \mathrm{~kg} / \mathrm{m}^{3}$ \\
Poisson's ratio & 0.2 \\
Span length & $15 \mathrm{~m}$ \\
\hline \hline
\end{tabular}

Fig. 10 shows the variation of the normalized static and dynamic displacements at the centre of the exterior girder of the bridge with the normalized position of the vehicle moving over the central girder. The figure shows the effects of increasing the speed of the vehicle on the dynamic response of the bridge. It is clear that, when the speed of the vehicle increases, the dynamic response completely deviate from the static one.

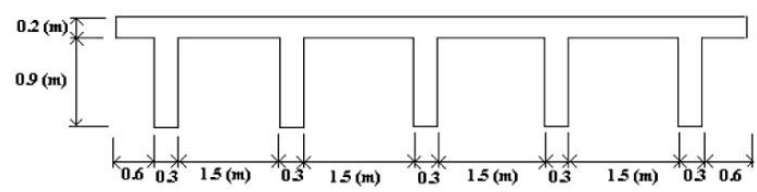

Fig. 8. Details of cross-section of deck girder bridge.

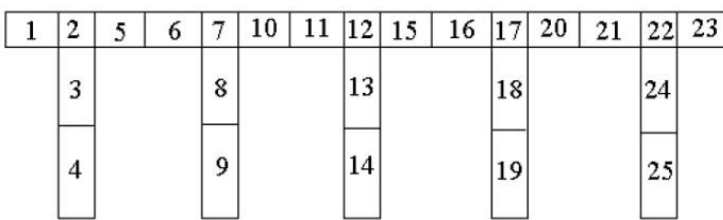

Fig. 9. Finite prism idealization of deck girder bridge.

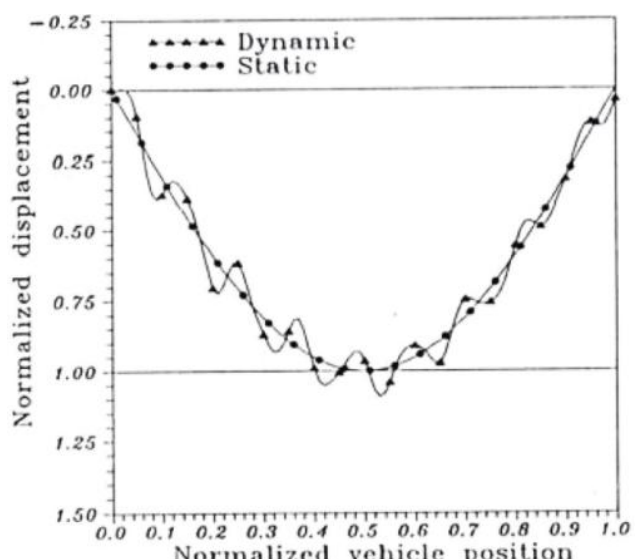

(a) Vehicle speed $=40 \mathrm{~km} / \mathrm{h}$.

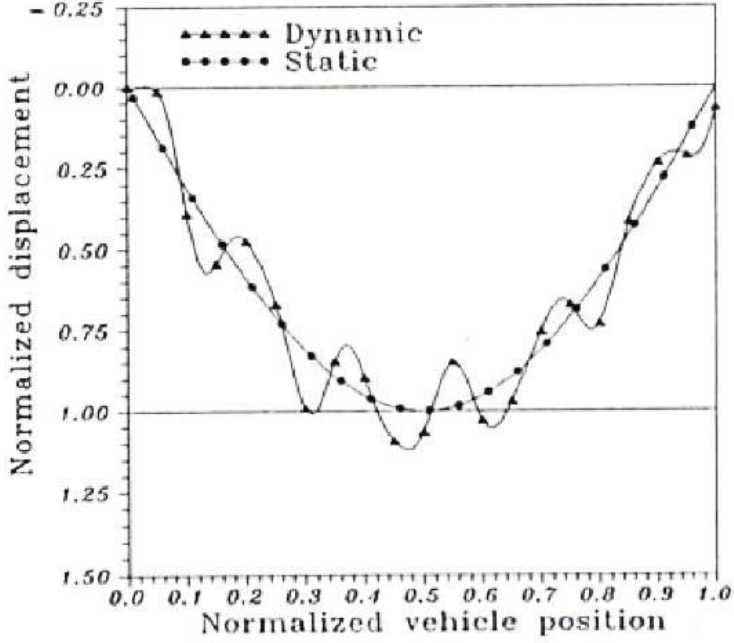

(b) Vehicle speed $=60 \mathrm{~km} / \mathrm{h}$.

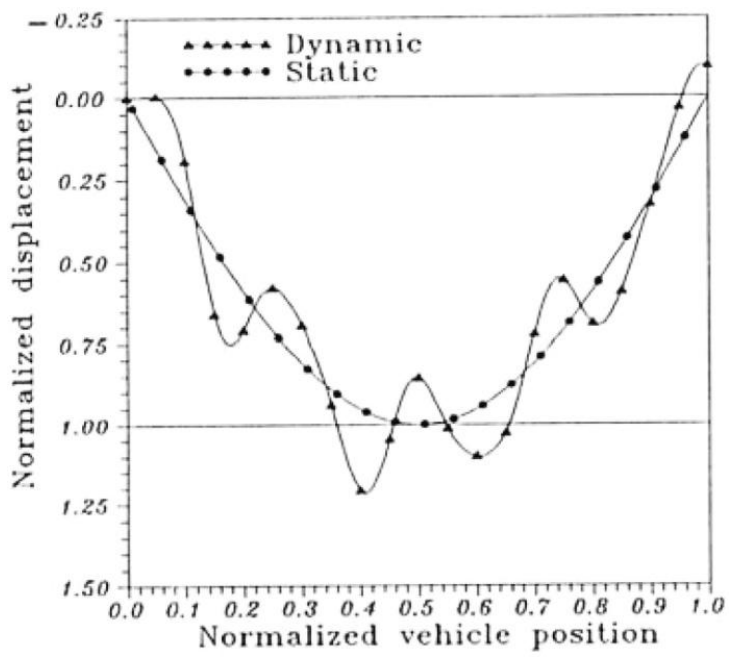

(c) Vehicle speed $=80 \mathrm{~km} / \mathrm{h}$.

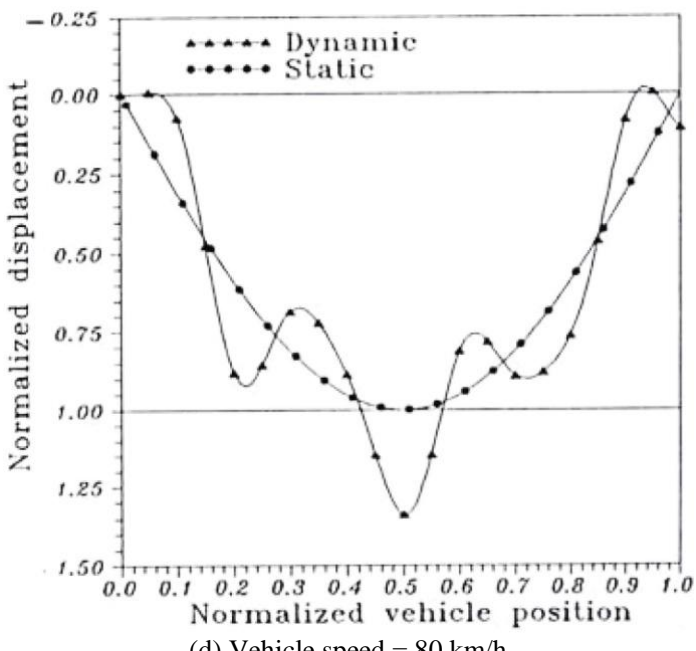

(d) Vehicle speed $=80 \mathrm{~km} / \mathrm{h}$

Fig. 10. Normalized static and dynamic centre displacements of exterior girder due to vehicle model moving over central girder.

\section{CONCLUSION}

A new model for the dynamic analysis of bridges due to moving vehicle was developed in this work. The model is based on the coupling of the explicit solution of the equation of motion with the harmonic solution of the finite prism method. 
Two different models for the vehicle are presented: the moving force model which is assumed to be constant during the traveling time of the vehicle along the span, and the moving vehicle model which takes into consideration the interaction between the bridge and the vehicle model. Numerical results from the developed computer code in the present study have shown good agreement with published data. The interaction of the vehicle with the bridge shows that the dynamic response of the bridge is significantly affected by the speed of the vehicle. Further studies in explicit transient analysis of bridges subjected to sudden and impulsive loadings are recommended using finite prism method.

\section{REFERENCES}

[1] O. C. Zienkiewics and J. J. M. Too, "The finite prism in analysis of thick simply supported bridge boxes," in Proc. Inst. of Civil Engineering, pp. 147-172, vol. 53, 1972.

[2] S. Y. Al-Darzi, "Static and free vibration analysis of bridges using finite prism method," M.Sc. Thesis, Dept Civil Eng., University of Mosul, Mosul, Iraq, 1998.

[3] A. T. Saeed, "Finite prism dynamic analysis of bridges," M.Sc. thesis, Dept of Civil Eng., University of Mosul, Mosul, Iraq, 2000.

[4] T. E. Blejwas, C. C. Feng and R. S. Ayre, "Dynamic interaction of moving vehicles and structures," Journal of Sound and Vibration, vol. 67, no. 4, pp. 513-521, 1979

[5] W. Weaver and P. R. Johnston, Structural Dynamics by Finite Elements , New Jersey: Prentice-Hall, Inc., 1987.

[6] S. P. Timoshenko and J. N. Goodier, Theory of Elasticity, 3rd ed. New York: McGraw- Hill Book Company, 1970.

[7] M. N. Mahmood, "Explicit dynamic analysis of mindlin plates using finite strip methods," Al-Rafidain Engineering, vol. 6, no. 1, pp. 1-10, 1998.

[8] D. R. J. Owen and E. Hinton, Finite Element in Plasticity: Theory and Practice, Swansea, U. K.: Pineridge Press Limited, 1980.

[9] J. M. Canet, B. Suarez and E. Onate, "Dynamic analysis of structures using a reissner-mindlin finite strip formulation," Computers and Structures, vol. 31, no. 6, pp. 967-975, 1989.

[10] J. Donea and H. Laval, "An improved formulation of the parabolic isoparametric element for explicit transient analysis," Earthquake Engineering and Structural Dynamics, vol. 7, pp. 23-29, 1979.

[11] R. D. Cook, Concepts and Application of Finite Element Analysis, 2nd ed. New York: John Wiley and Sons. Inc., 1981.

[12] E. Hinton, T. Rock and O. C. Zienkiewics, "A note on mass lumping and related processes in the finite element method," Earthquake Engineering and Structural Dynamics, vol. 4, pp. 245-249, 1976.
[13] K. Chompooming and M. Yener, "The influence of roadway surface irregularities and vehicle deceleration on bridge dynamics using the method of lines," Journal of Sound and Vibration, vol. 183, no. 4, pp. $567-589,1995$

[14] M. J. Inbanathan and M. Wieland, "Bridge vibrations due to vehicles moving over rough surface," Journal of Structural Engineering, vol. 113, no. 9, pp. 1994-2008, 1987.

[15] J. W. Kou and J. T. DeWolf, "Vibrational behavior of continuous span highway bridge-influencing variables," Journal of Structural Engineering, vol. 123, no. 3, pp. 333-344, 1997.

[16] V. Mermertas, "Dynamic interaction between the vehicle and simply supported curved bridge deck," Computer Method in Applied Mechanics and Engineering, vol. 162, pp. 125-131, 1998

[17] T. Y. Tsui and P. Tong, "Stability of transient solution of moderately thick plate by finite difference method," AIAA Journal, vol. 9, no. 10, pp. 2062-2063, 1971.

[18] R. S. Srinivasan and K. Munaswamy, "Dynamic response of skew bridge decks," Earthquake Engineering and Structural Dynamics, vol. 6, pp. 139-156, 1978

[19] Y. Cai, S. S. Chen, D. M. Rote, and H. T. Coffy, "Vehicle/guideway interaction for high speed vehicles on a flexible guideway," Journal of Sound and Vibration, vol. 175, no. 5, pp. 625-646, 1994.

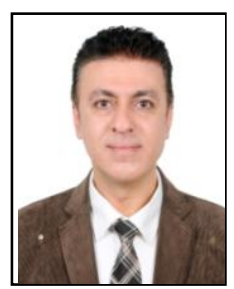

A. T. Saeed was born in Iraq in 1975 . He earned his $\mathrm{Ph} . \mathrm{D}$. degree in bridge and tunnel engineering from Chongqing University, China in 2011.

$\mathrm{He}$ is a lecturer and postdoctoral research fellow in the field of civil engineering at Chongqing Jiaotong University, China and he has been working as lecturer at Mosul University, Iraq. He worked as a postdoctoral research fellow at T.Y.Lin International Engineering Consulting (China) Co., Ltd in cooperation with Chongqing University, China. His main research interests are in the area of dynamic analysis of coupled wind-vehicle-bridge systems and dynamic analysis of fluid-structures interaction systems.

Dr. Saeed is a member of Association for Science and Technology of T.Y.Lin International Engineering Consulting (China) Co., Ltd

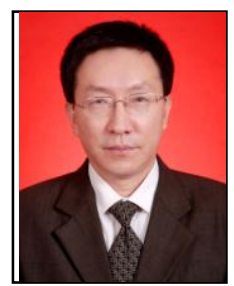

Zhongfu Xiang was born in China in 1960. He earned his M.Sc. degree in bridge and tunnel engineering from Chongqing Jiaotong College, China in 1990.

$\mathrm{He}$ is a professor in the field of civil engineering at Chongqing Jiaotong University, China, the director of the bridge and structural engineering research centre of the Ministry of education in the mountainous areas, and the leader of academic technologies in the Chongqing city. He is mainly engaging in the teaching of bridge engineering and design theory. His main research interests are in the area of the construction and control technology. 